\title{
Hormone Replacement Therapy for Restoring the HPG Axis in Pain Patients Treated with Long-Term Opioid Analgesics*
}

\author{
Srinivas Nalamachu1, Joseph V. Pergolizzi Jr. ${ }^{2,3}$, Robert Taylor Jr. ${ }^{2}$, Jo Ann Le Quang4, \\ Joseph V. Pergolizzi III², Robert B. Raffa ${ }^{5,6}$
}

\author{
${ }^{1}$ International Clinical Research, Institute and Pain Management Institute, Overland Park, KS, USA \\ ${ }^{2}$ NEMA Research, Inc., Naples, FL, USA \\ ${ }^{3}$ Neumentum, Inc., Palo Alto, CA, USA \\ ${ }^{4}$ LeQ Medical, Angleton, TX, USA \\ ${ }^{5}$ College of Pharmacy, University of Arizona, Tucson, AZ, USA \\ ${ }^{6}$ School of Pharmacy, Temple University, Philadelphia, PA, USA \\ Email: robert.raffa@temple.edu
}

How to cite this paper: Nalamachu, $S$. Pergolizzi Jr., J.V., Taylor Jr., R., Quang, J.A.L., Pergolizzi III, J.V. and Raffa, R.B. (2018) Hormone Replacement Therapy for Restoring the HPG Axis in Pain Patients Treated with Long-Term Opioid Analgesics. Pharmacology \& Pharmacy, 9, 473-480. https://doi.org/10.4236/pp.2018.911036

Received: October 13, 2018

Accepted: November 10, 2018

Published: November 13, 2018

Copyright $\odot 2018$ by authors and Scientific Research Publishing Inc. This work is licensed under the Creative Commons Attribution International License (CC BY 4.0).

http://creativecommons.org/licenses/by/4.0/

\begin{abstract}
Opioids are a treatment option for a variety of chronic pain conditions. But long-term opioid use can be associated with side effects, including hypogonadism. Opioid-induced hypogonadism (OIhG) is associated with the alteration of the hypothalamic-pituitary-gonadal axis (HPG). In males, hypogonadism can result in erectile dysfunction, reduced libido, fatigue, worsening mood, and increased risk of osteoporosis; in females, it can result in changes in the menstrual cycle and reduced libido, among other effects. A current treatment option for these patients is hormone replacement therapy. In this report, we discuss the problem of opioid-induced hypogonadism, and the therapeutic approach and the potential complications of treating pain patients using hormone replacement therapy.
\end{abstract}

\section{Keywords}

Opioid Therapy, Chronic Pain, HPG Axis, Hormone Replacement Therapy

\section{Introduction}

Opioids are an option for pain management for the chronic pain patient, with generally, albeit not always, good effectiveness [1]. Unfortunately, patients on long term opioid therapy often experience the well-known typical opioid-related

${ }^{\star}$ A preliminary version of this work appeared in Painview 9(1): 14-15, 2013. 
side effects of constipation, nausea, vomiting, and sedation [2]. In addition, however, some experience the less well-known opioid side effect of hypogonadism (OIhG) [3]. OIhG is extensively documented in animal models [4] [5] [6] and in human studies [7] [8] [9] [10] [11]. OIgH and the associated physiological effects (disruption of hormonal balance) result from the action of opioids on opioid receptors located within the hypothalamus. Cases of OIgH were observed in heroin and methadone abusers in the 1970s [12]. Estimates of OIhG prevalence in long-term use by chronic pain patients range from $21 \%$ to $86 \%$ [7] [9] [10] [11] [13] [14] [15], with males more frequently than females experiencing OIhG. As an example, in a recent study, $75 \%$ of males and $21 \%$ of females taking oral opioids for chronic non-cancer pain had hypogonadism [11].

Common OIgH effects experienced by males include reduction in the levels of testosterone, which can lead to effects such as muscle hypotrophy, loss of bone mass, anemia, etc., and/or central effects such as decreased attention, decreased libido, depression, etc. Some common OIgH effects experienced by females include irregular periods and amenorrhea, which is caused by reduced levels of luteinizing hormone, follicle stimulating hormone, oestradiol, and adrenal androgen [10]. Effects such as flushing, sweating, decreased libido, infertility, osteopenia, osteoporosis, and depression may occur in both genders [16]. Furthermore, OIhG might also increase the risk for development of Alzheimer disease and rheumatoid arthritis [17] [18].

We reviewed publications available in English language using sources such as PubMed, MedLine, and related. We used search terms such as opioid, chronic hypogonadism, hormone replacement therapy, chronic pain, and HPG axis. Additional articles were identified from references therein. All were reviewed for applicability and quality of evidence.

\section{HPG Axis and the Effects of Opioids}

$\mathrm{OIgH}$ results from the central suppression of the hypothalamic secretion of gonadotropin-releasing hormone $(\mathrm{GnRH})$ by opioid agonists (endogenous or exogenous) acting at opioid receptors located within the hypothalamus (Figure 1) [19]. This in turn reduces the secretion of luteinizing hormone (LH) and follicle stimulating hormone (FSH) from pituitary gland, which then inhibits the production of testosterone and estradiol from gonads. The chain of events can occur fairly rapidly (within hours) from the onset of opioid use [13] [14], and continuous reduction in hormone secretion can accompany sustained opioid use for chronic pain [15].

Disruption of gonadal hormone balance usually results in physical and mental changes. In a study of 54 males taking opioids, $87 \%$ reported severe erectile dysfunction (they had normal erectile function prior to opioid treatment) and/or diminished libido. It was found that $89 \%$ of the males had decreased levels of free testosterone, oestradiol, dihydrotestosterone, LH, and FSH [9]. In a study of female pain patients receiving opioids, more than half experienced a disruption 

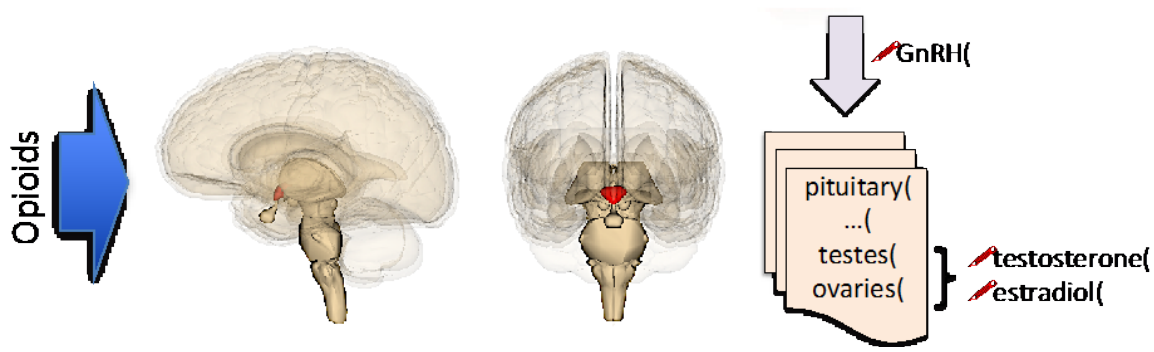

Figure 1. Opioid action on the HPG axis reduces sex hormone action. 3-D view from Wikimedia Commons.

of menses, an effect that the authors believed to be caused by the recorded reduction in LH, FSH, oestradiol and adrenal androgen [10].

In another study, $96 \%$ and $69 \%$ of males and females, respectively, reported decreased libido after being administered opioids for 26 months for non-cancer chronic pain [7]. In addition, psychological symptoms associated with hypogonadism may include anxiety, stress, insomnia, and depression (low levels of testosterone have been observed in depressed patients) [20] [21] [22]. In order to prevent or mitigate the symptoms of OIhG in long-term opioid treatment, hormone replacement therapy is an option that is often considered.

\section{Hormone Replacement Therapy}

When OIhG is diagnosed in chronic pain patients, it might be treated using hormone replacement therapy. Replacement of testosterone or oestradiol may relieve the acute symptoms of OIhG and also prevent the long-term consequences associated with untreated OIhG. Although there is lack of definitive evidence regarding the effectiveness and safety of hormone replacement therapy for $\mathrm{OIgH}$ in chronic pain patients, there are sufficient current literature reports of positive results for efficacy and safety to suggest that additional, controlled studies are warranted.

In a study conducted by Daniell et al., testosterone replacement improved sexual function of males with OIhG [23]. During this 24-week open-label pilot study using a testosterone patch, 23 males with opioid-induced androgen deficiency (OPIAD) were treated. The patch dosage was $5 \mathrm{mg} / \mathrm{day}$ for the first 12 weeks and $7.5 \mathrm{mg} /$ day for the second 12 weeks. In the "completers" population $(\mathrm{n}=16)$, mean (SD) free testosterone levels (normal range 52 to $280 \mathrm{pg} / \mathrm{mL}$ ) were $28.5(18.6) \mathrm{pg} / \mathrm{mL}$ at baseline, $72.8(29.6) \mathrm{pg} / \mathrm{mL}$ on $5 \mathrm{mg} /$ day $(\mathrm{P}<0.001 \mathrm{vs}$. baseline), and $120.2(69.5) \mathrm{pg} / \mathrm{mL}$ on $7.5 \mathrm{mg} /$ day $(\mathrm{P}<0.001$ vs. baseline and $\mathrm{P}<$ 0.01 vs. $5 \mathrm{mg} /$ day). Total testosterone, dihydrotestosterone, and estradiol showed parallel changes. Sex hormone-binding globulin levels were elevated at baseline and decreased modestly with treatment $(\mathrm{P}<0.05$ vs. baseline at 5 $\mathrm{mg} /$ day; $\mathrm{P}<0.01$ vs. baseline at $7.5 \mathrm{mg} /$ day). Luteinizing hormone levels were in the low-normal range at baseline and suppressed markedly with treatment $(\mathrm{P}<$ 0.001 vs. baseline at both doses). Androgen deficiency symptoms (ADSQ), sexual function (Watts SFQ), mood (PGWB), depression (BDI-II), and hematocrit 
levels showed improvement during treatment, generally more so at the $7.5 \mathrm{mg} /$ day dosage ( $\mathrm{P}<0.001$ vs. baseline for most parameters). Pain scores (BPI-SF) decreased slightly on $7.5 \mathrm{mg} /$ day (interference score: $\mathrm{P}<0.05$ vs. baseline and 5 $\mathrm{mg} /$ day); the use of opioids did not change appreciably. The authors concluded that testosterone patch therapy at a dose of $7.5 \mathrm{mg} /$ day restored the normal hormone balance and in turn helped improve patients' quality of life. In another small study conducted by Aloisi et al., chronic pain patients receiving epidural morphine received testosterone replacement therapy for up to 12 months [24]. The daily administration of testosterone increased total and free testosterone as well as DHT after 3 months of treatment. Continuation up to 12 months of treatment maintained the hormone levels. In addition, pain-rating indexes (QUID) progressively improved from 3 to 12 months while other pain parameters (VAS, Area\%) remained unchanged. The AMS sexual dimension and SF-36 Mental Index displayed a significant improvement over time. Based on the evidence from this study, the authors concluded that one year of testosterone replacement therapy helped male patients diagnosed with morphine-induced hypogonadism.

Overall, these studies suggest that testosterone replacement may be a safe and effective treatment option for opioid users. Additional studies are needed.

\subsection{Clinical Practice Overview}

There is a variety of options to choose from for testosterone replacement therapy, including gels, lotions, creams, intramuscular injections, and implantation devices (every 4 - 6 months). The dosage and treatment regimens of these products vary, but the main goal is to return testosterone level to $\sim 500 \mathrm{ng} / \mathrm{dL}$ (the normal range is $\sim 250-1000 \mathrm{ng} / \mathrm{dL}$ ). Patients normally continue on treatment until contradictions or side effects develop (e.g., lower leg edema, breast enlargement, or prostate enlargement with difficulty urinating), but patients can often remain on replacement therapy effectively and safely for many years. Patients usually report improvement in mood, desirable weight loss, rise in testosterone levels, better libido, increased sex drive, better erections, and more energy. The beneficial effects and good safety profile usually translate to high patient satisfaction. The case reports presented below exemplify some positive outcomes associated with testosterone replacement.

\subsection{Case Reports}

Case \#1: A 61 year-old man presented with symptoms associated with OIhG. His medical history consisted of depression, insomnia, and anxiety; surgical history consisted of tonsillectomy, a left shoulder open reduction, and right quadrant hernia repair. The patient was diagnosed with chronic low back pain in early 2011 and was taking dilaudid for approximately one year to control back pain. Other medications included well butrin, desoril, and vistaril for depression, insomnia, and anxiety respectively. The patient sought help because of reduced energy, feeling of depression, and lower sexual drive. Testosterone levels, hema- 
tocrit level, and PSA level were $188 \mathrm{ng} / \mathrm{dL}, 42.5 \%$ and $1.1 \mathrm{ng} / \mathrm{mL}$ respectively. The patient completed a sexual desire inventory questionnaire (score 26) and Becks Depression Inventory Scale (score 16, mild depression) in order to establish baseline values before treatment. The patient was started on $40 \mathrm{mg} /$ day of a testosterone gel. After approximately 2 weeks of treatment, his testosterone levels had risen to $1241 \mathrm{ng} / \mathrm{dL}$; however, the patient did not report feeling much different and the sexual desire inventory (SDI) and Becks depression inventory (BDI) score remained approximately the same $(\mathrm{SDI}=23, \mathrm{BDI}=20)$. At about one month of treatment, his testosterone level was $1154 \mathrm{ng} / \mathrm{dL}$ and he began reporting increased energy and increased sexual desire. The SDI score increased to 58 , indicating improvement, while the BDI was similar to previous readings. After 2 months of treatment, testosterone level was $737 \mathrm{ng} / \mathrm{dL}$, BDI score 15, and SDI score 78, which correlated with the patient's description of increased libido. While on treatment, the patient did not have any undesirable side effects and his vital signs remained unchanged. Patient satisfaction was excellent and the patient expressed a desire to continue with longer-term treatment.

Case \#2: A 42 year-old man sought help due to decreased sexual desire, fatigue, and lack of muscle strength. His medical history consisted of right knee pain, left side paralysis, spinal cord injury, tracheotomy, anemia, and erectile dysfunction. The patient was diagnosed with osteoarthritis in 2000. He was taking Exalgo, oxycodone, cialis, and iron sulfate supplement for right knee pain, osteoarthritis, erectile dysfunction, and anemia, respectively. Prior to starting testosterone replacement, baseline assessments for total testosterone, hematocrit level, and PSA level were $182 \mathrm{ng} / \mathrm{dL}, 40.9 \%$, and $0.2 \mathrm{ng} / \mathrm{dL}$. The patient also completed baseline SDI (score 40) and BDI (24, moderately depressed). Based on this information, prescription for $40 \mathrm{mg} /$ day testosterone gel was written. After approximately 2 weeks of treatment, testosterone level was $975 \mathrm{ng} / \mathrm{dL}$ and the patient reported feeling a noticeable change in his core muscles, increased energy, feeling rested after sleeping, and an increase in sexual drive. The SDI score increased to 63 and the BDI score decreased to 14. Complaints included nightly calf cramps during first week of medication (that resolved by the end of 2 weeks). After two months of treatment, testosterone level was $1096 \mathrm{ng} / \mathrm{dL}$ and the patient continued to notice increase in energy level, increase in sexual desire, and improvement of his left side paralysis. The SDI score was 78 and BDI score was 14 . The patient was very satisfied with the treatment and had intentions to continue for a longer term.

Case \#3: A 30 year-old morbid obese male chronic pain patient was looking to improve his energy level, weight control, and sexual desire. His medical history consisted of herniated disks, lumbar fusion, tonsillitis, tonsillectomy, cluster headaches, anxiety, right arthroscopic knee surgery, failed back syndrome, degenerative arthritis of the knees, constipation, lower extremity edema, muscle spasms, and neuropathy of the lower extremities. The patient was diagnosed with degenerative disk disease in 2008. Concomitant medications included oxycodone, tizanidine, ibuprofen, verapamil, morphine, xanax, soma, and aquaphor for failed 
back syndrome, muscle spasms, pain preventative, cluster headaches, degenerative spine disease, anxiety, muscle spasms, and dry skin, respectively. Baseline assessments included total testosterone (17 ng/dL), hematocrit (44.6\%), PSA level (0.7 ng/dL), SDI questionnaire (46), and BDI questionnaire (19). The patient was initiated on $40 \mathrm{mg} /$ day testosterone gel and after 2 weeks he noticed a change in his energy and sexual desire. Total testosterone improved to $709 \mathrm{ng} / \mathrm{dL}$. After approximately one month, total testosterone improved to $1269 \mathrm{ng} / \mathrm{dL}$ and SDI and BDI improved to 60 and 11, respectively. After approximately two months, total testosterone was $634 \mathrm{ng} / \mathrm{dL}$ and SDI and BDI were 59 and 25, respectively. The patient was overall satisfied with the medication and noticed improvement in energy, muscle tone, and sexual desire. The only safety issue reported was dry skin at the application site.

Hormone replacement therapy is not without complications. Men receiving hormone replacement therapy should be monitored for side-effects such as polycythemia, peripheral edema, cardiac and hepatic dysfunction.

\section{Conclusion}

Long-term administration of opioids in chronic pain patients can alter the HPG axis in both males and females, resulting in physical and psychological symptoms of OIgH (opioid-induced hypogonadism). Effects of OIgH such as reduced sexual drive, fatigue, and insomnia can lead to a reduction in quality of life and, in combination with the hormonal imbalance, can increase the risk of developing depression and other psychological and physical disorders. Replacement of testosterone in these patients might be a viable option for reversing many of these side effects. Reports from small trials and clinical case reports suggest that androgen replacement therapy might be an effective and safe treatment for long-term pain patients treated with opioids. Large controlled clinical trials are needed.

\section{Acknowledgements}

The authors thank John Bisney of LeQ Medical (Angleton, TX) for his excellent editorial assistance.

\section{Conflicts of Interest}

The authors declare no conflicts of interest regarding the publication of this paper.

\section{References}

[1] Manchikanti, L., Vallejo, R., Manchikanti, K.N., Benyamin, R.M., Datta, S. and Christo, P.J. (2011) Effectiveness of Long-Term Opioid Therapy for Chronic Non-Cancer Pain. Pain Physician, 14, E133-E156. https://www.ncbi.nlm.nih.gov/pubmed/21412378

[2] Furlan, A.D., Sandoval, J.A., Mailis-Gagnon, A. and Tunks, E. (2006) Opioids for Chronic Noncancer Pain: A Meta-Analysis of Effectiveness and Side Effects. Cana- 
dian Medical Association Journal, 174, 1589-1594.

https://www.ncbi.nlm.nih.gov/pubmed/16717269

https://doi.org/10.1503/cmaj.051528

[3] Benyamin, R., et al. (2008) Opioid Complications and Side Effects. Pain Physician, 11, S105-S120. https://www.ncbi.nlm.nih.gov/pubmed/18443635

[4] Ceccarelli, I., De Padova, A.M., Fiorenzani, P., Massafra, C. and Aloisi, A.M. (2006) Single Opioid Administration Modifies Gonadal Steroids in Both the CNS and Plasma of Male Rats. Neuroscience, 140, 929-937.

https://www.ncbi.nlm.nih.gov/pubmed/16580783

https://doi.org/10.1016/j.neuroscience.2006.02.044

[5] Ceccarelli, I., Rossi, A., Maddalena, M., Weber, E. and Aloisi, A.M. (2009) Effects of Morphine on Testosterone Levels in Rat C6 Glioma Cells: Modulation by Anastrozole. Journal of Cellular Physiology, 221, 1-4. https://doi.org/10.1002/jcp.21830 https://onlinelibrary.wiley.com/doi/abs/10.1002/jcp.21830

[6] Amini, H. and Ahmadiani, A. (2005) In Vivo Evidence for an Increase in 5 Alpha-Reductase Activity in the Rat Central Nervous System Following Morphine Exposure. International Journal of Developmental Neuroscience, 23, 621-626.

https://kundoc.com/pdf-in-vivo-evidence-for-an-increase-in-5alpha-reductase-activ ity-in-the-rat-central.html https://doi.org/10.1016/j.ijdevneu.2005.07.001

[7] Abs, R., et al. (2000) Endocrine Consequences of Long-Term Intrathecal Administration of Opioids. Journal of Clinical Endocrinology and Metabolism, 85, 2215-2222. https://www.ncbi.nlm.nih.gov/pubmed/10852454 https://doi.org/10.1210/jcem.85.6.6615

[8] Aloisi, A.M., et al. (2005) Gender-Related Effects of Chronic Non-Malignant Pain and Opioid Therapy on Plasma Levels of Macrophage Migration Inhibitory Factor (MIF). Pain, 115, 142-151. https://www.ncbi.nlm.nih.gov/pubmed/15836977 https://doi.org/10.1016/j.pain.2005.02.019

[9] Daniell, H.W. (2002) Hypogonadism in Men Consuming Sustained-Action Oral Opioids. Journal of Pain, 3, 377-384. https://doi.org/10.1054/jpai.2002.126790 https://www.ncbi.nlm.nih.gov/pubmed/14622741

[10] Daniell, H.W. (2008) Opioid Endocrinopathy in Women Consuming Prescribed Sustained-Action Opioids for Control of Nonmalignant Pain. Journal of Pain, 9, 28-36. https://www.ncbi.nlm.nih.gov/pubmed/17936076 https://doi.org/10.1016/j.jpain.2007.08.005

[11] Fraser, L.A., et al. (2009) Oral Opioids for chronic Non-Cancer Pain: Higher Prevalence of Hypogonadism in Men than in Women. Experimental and Clinical Endocrinology \& Diabetes, 117, 38-43. https://www.ncbi.nlm.nih.gov/pubmed/18523930 https://doi.org/10.1055/s-2008-1076715

[12] Azizi, F., Vagenakis, A.G, Longcope, C., Ingbar, S.H. and Braverman, L.E. (1973) Decreased Serum Testosterone Concentration in Male Heroin and Methadone Addicts. Steroids, 22, 467-472. https://doi.org/10.1016/0039-128X(73)90002-0

[13] Mendelson, J.H., Ellingboe, J., Judson, B.A. and Goldstein, A. (1984) Plasma Testosterone and Luteinizing Hormone Levels during Levo-Alpha-Acetylmethadol Maintenance and Withdrawal. Clinical Pharmacology \& Therapeutics, 35, 545-547. https://doi.org/10.1038/clpt.1984.75

[14] Woody, G., McLellan, A.T., O’Brien, C., Persky, H., Stevens, G., Arndt, I. and Carroff, S. (1988) Hormone Secretion in Methadone-Dependent and Abstinent Patients. NIDA Research Monograph, 81, 216-223. 
[15] Roberts, L.J., Finch, P.M., Pullan, P.T., Bhagat, C.I. and Price, L.M. (2002) Sex Hormone Suppression by Intrathecal Opioids: A Prospective Study. Clinical Journal of Pain, 18, 144-148. https://www.ncbi.nlm.nih.gov/pubmed/12048415 https://doi.org/10.1097/00002508-200205000-00002

[16] Vestergaard, P., Rejnmark, L. and Mosekilde, L. (2006) Fracture Risk Associated with the Use of Morphine and Opiates. Journal of Internal Medicine, 260, 76-87. https://www.ncbi.nlm.nih.gov/pubmed/16789982 https://doi.org/10.1111/j.1365-2796.2006.01667.x

[17] Moffat, S.D., et al. (2004) Free Testosterone and Risk for Alzheimer Disease in Older Men. Neurology, 62, 188-193. https://www.ncbi.nlm.nih.gov/pubmed/14745052 https://doi.org/10.1212/WNL.62.2.188

[18] Straub, R.H. and Cutolo, M. (2001) Involvement of the Hypothalamic-Pituitary-Adrenal/Gonadal Axis and the Peripheral Nervous System in Rheumatoid Arthritis: Viewpoint Based on a Systemic Pathogenetic Role. Arthritis \& Rheumatology, 44, 493-507. https://www.ncbi.nlm.nih.gov/pubmed/11263762 https://doi.org/10.1002/1529-0131(200103)44:3<493::AID-ANR95>3.0.CO;2-U

[19] Vuong, C., Van Uum, S.H., O’Dell, L.E., Lutfy, K. and Friedman, T.C. (2010) The Effects of Opioids and Opioid Analogs on Animal and Human Endocrine Systems. Endocrine Reviews, 31, 98-132. https://www.ncbi.nlm.nih.gov/pubmed/19903933

[20] Osran, H., et al. (1993) Adrenal Androgens and Cortisol in Major Depression. American Journal of Psychiatry, 150, 806-809. https://doi.org/10.1176/ajp.150.5.806

[21] Seidman, S.N. and Walsh, B.T. (1999) Testosterone and Depression in Aging Men. The American Journal of Geriatric Psychiatry, 7, 18-33.

https://www.ncbi.nlm.nih.gov/pubmed/9919317 https://doi.org/10.1097/00019442-199902000-00004

[22] Zarrouf, F.A., Artz, S., Griffith, J., Sirbu, C. and Kommor, M. (2009) Testosterone and Depression: Systematic Review and Meta-Analysis. Journal of Psychiatric Practice, 15, 289-305. https://www.ncbi.nlm.nih.gov/pubmed/19625884 https://doi.org/10.1097/01.pra.0000358315.88931.fc

[23] Daniell, H.W., Lentz, R. and Mazer, N.A. (2006) Open-Label Pilot Study of Testosterone Patch Therapy in Men with Opioid-Induced Androgen Deficiency. The Journal of Pain, 7, 200-210. https://www.ncbi.nlm.nih.gov/pubmed/16516826 https://doi.org/10.1016/j.jpain.2005.10.009

[24] Aloisi, A.M., et al. (2011) Hormone Replacement Therapy in Morphine-Induced Hypogonadic Male Chronic Pain Patients. Reproductive Biology and Endocrinolo$g y$, 9, 26. https://doi.org/10.1186/1477-7827-9-26 